\title{
"Code Switching" in Sociocultural Linguistics
}

\author{
Chad Nilep \\ University of Colorado, Boulder
}

\begin{abstract}
This paper reviews a brief portion of the literature on code switching in sociology, linguistic anthropology, and sociolinguistics, and suggests a definition of the term for sociocultural analysis. Code switching is defined as the practice of selecting or altering linguistic elements so as to contextualize talk in interaction. This contextualization may relate to local discourse practices, such as turn selection or various forms of bracketing, or it may make relevant information beyond the current exchange, including knowledge of society and diverse identities.
\end{abstract}

\section{Introduction}

The term code switching (or, as it is sometimes written, code-switching or codeswitching) ${ }^{1}$ is broadly discussed and used in linguistics and a variety of related fields. A search of the Linguistics and Language Behavior Abstracts database in 2005 shows more than 1,800 articles on the subject published in virtually every branch of linguistics. However, despite this ubiquity - or perhaps in part because of it - scholars do not seem to share a definition of the term. This is perhaps inevitable, given the different concerns of formal linguists, psycholinguists, sociolinguists, philosophers, anthropologists, etc. This paper will attempt to survey the use of the term code switching in sociocultural linguistics and suggest useful definitions for sociocultural work.

Since code switching is studied from so many perspectives, this paper will necessarily seem to omit important elements of the literature. Much of the work labeled "code switching" is interested in syntactic or morphosyntactic constraints on language alternation (e.g. Poplack 1980; Sankoff and Poplack 1981; Joshi 1985; Di Sciullo and Williams 1987; Belazi et al. 1994; Halmari 1997 inter alia). Alternately, studies of language acquisition, second language acquisition, and language learning use the term code switching to describe either bilingual speakers' or language learners' cognitive linguistic abilities, or to describe classroom or learner practices involving the use of more than one language (e.g. Romaine 1989; Cenoz and Genesee 2001; Fotos 2001, inter alia). These and other studies seem to use code as a synonym for language variety. Alvarez-Cáccamo

\footnotetext{
${ }^{1}$ My personal preference is to spell code switching as two words, with white space between them, a practice I will generally follow throughout this paper. Original spelling will be preserved in quotations and when paraphrasing scholars who routinely use an alternate form.
}

Colorado Research in Linguistics. June 2006. Vol. 19. Boulder: University of Colorado.

(C) 2006 by Chad Nilep. 
(2000) argues that this equation may obscure certain interactional functions of such alternation.

Practically all work on "code-switching," or changing codes, has been based on a strict identification between the notions of "code" and "linguistic variety," be that a language, dialect, style, or prosodic register. However, this structural focus fails to convincingly explain certain conversational phenomena relative to the relevance or significance (or lack of relevance) of alternations between contrasting varieties. [Alvarez-Cáccamo 2000:112; my translation]

Certainly, the study of language alternation has been fruitful over the past several decades. The identification of various constraints, though sometimes controversial, has inspired a great deal of work in syntax, morphology, and phonology. A structural focus has been similarly constructive for production models (e.g. Azuma 1991) or as evidence for grammatical theory (e.g. MacSwann 2000; Jake, Myers-Scotton and Gross 2002). By ignoring questions of function or meaning, though, this structural focus fails to answer basic questions of why switching occurs. ${ }^{2}$ Auer (1984) warns, "Grammatical restrictions on codeswitching are but necessary conditions" (2); they are not sufficient to describe the reason for or effect of a particular switch. If linguists regard code switching simply as a product of a grammatical system, and not as a practice of individual speakers, they may produce esoteric analyses that have little importance outside the study of linguistics per se, what Sapir called "a tradition that threatens to become scholastic when not vitalized by interests which lie beyond the formal interest in language itself" (1929:213). This paper is thus positioned within the discipline of sociocultural linguistics, an emerging (or one might say, revitalized) approach to linguistics that looks beyond formal interests, to the social and cultural functions and meanings of language use.

Periodically over the last century, linguists have proposed to bring their own studies closer to other fields of social inquiry. In 1929, Edward Sapir urged linguists to move beyond diachronic and formal analyses for their own sake and to "become aware of what their science may mean for the interpretation of human conduct in general" (1929:207). He suggested that anthropology, sociology, psychology, philosophy and social science generally would be enriched by drawing on the methodologies as well as the findings of linguistic research. He also exhorted linguists to consider language within its broader social setting.

\footnotetext{
${ }^{2}$ Woolard (2004) suggests that the basic question should be not why speakers make use of the various forms available to them, but why speakers would not make use of all available forms. Thus she suggests, "It could be argued that linguists, with their focus on constraints against rather than motivations for codeswitching, do ask this alternative question" (91).
} 
It is peculiarly important that linguists, who are often accused, and accused justly, of failure to look beyond the pretty patterns of their subject matter, should become aware of what their science may mean for the interpretation of human conduct in general. Whether they like it or not, they must become increasingly concerned with the many anthropological, sociological, and psychological problems which invade the field of language. [Sapir 1929:214]

Sapir was not alone in his hopes for a more socially engaged linguistics. Indeed the development of sociolinguistics and psycholinguistics during the 1930s-1950s suggests that, at least for some linguists, social interaction and human cognition were as important as the forms and structures of language itself.

Nonetheless, by the 1960s some scholars once again felt the need to argue for a more socially engaged linguistics. In a special issue of American Anthropologist, Hymes (1964) lamented that the socially integrated linguistics Sapir had called for was disappearing. Hymes and others worried that new formal approaches, as well as the push for linguistics as an autonomous field, threatened to once again isolate linguists. At the same time, though, the growth of ethnolinguistics and sociolinguistics offered a venue for the socially engaged linguistics Sapir had called for four decades earlier.

Four more decades have passed, and once again scholars are calling for a revitalization of socially and culturally oriented linguistic analysis. Bucholtz and Hall (2005) position their own work on language and identity as what they call sociocultural linguistics, "the broad interdisciplinary field concerned with the intersection of language, culture, and society" (5). Just as Hymes (1964) worried that linguistics had been bleached of its association with the study of human interaction in the wake of formalist studies, Bucholtz and Hall point out that sociolinguistics has in turn been narrowed to denote only specific types of study. Sociocultural linguistics is thus suggested as a broader term, to include sociolinguistics, linguistic anthropology, discourse analysis, and sociology of language, as well as certain streams of social psychology, folklore studies, media studies, literary theory, and the philosophy of language.

What follows is a brief survey of work on the topic of code switching within sociocultural linguistics, followed by my own suggested definition for the term. I hope this definition will serve as a basis and context for sociocultural discussions of the contextualizing functions of language alternation and modulation.

\section{Foundational Studies}

\subsection{Early studies: The emergence of code switching}

The history of code switching research in sociocultural linguistics is often dated from Blom and Gumperz's (1972) "Social meaning in linguistic structures" (e.g. Myers-Scotton 1993; Rampton 1995; Benson 2001). This work is certainly 
important and influential, not least for introducing the terms situational and metaphorical switching (see below). However, by 1972 the term "code switching" was well attested in the literature, and several studies in linguistic anthropology and sociolinguistics prefigured later code switching research in sociocultural linguistics. Below, I survey some important early work.

One of the earliest American studies in linguistic anthropology to deal with issues of language choice and code switching was George Barker's (1947) description of language use among Mexican Americans in Tucson, Arizona. In addition to his analysis of the economic relations, social networks, and social geography of Tucson residents, Barker sought to answer the question, "How does it happen, for example, that among bilinguals, the ancestral language will be used on one occasion and English on another, and that on certain occasions bilinguals will alternate, without apparent cause, from one language to another?" (1947:18586). Barker suggested that interactions among family members or other intimates were most likely to be conducted in Spanish, while formal talk with AngloAmericans was most likely to use the medium of English (even when all parties in the interaction were able to understand Spanish). In less clearly defined situations, language choice was less fixed, and elements from each language could occur. Further, Barker proposed that younger people were more apt to use multiple languages in a single interaction than were their elders, and that the use of multiple varieties was constitutive of a local Tucson identity.

An important base for code switching research in the field of linguistics is Uriel Weinreich's (1953) Languages in Contact. One of those inspired by Weinreich's book was Hans Vogt, whose "Language Contacts" (1954) is cited as the first article to use the term "code-switching" in the field of linguistics (Alvarez-Cáccamo 1998; Benson 2001).

Weinreich was interested to describe the effect of language contact on languages, in addition to describing the activities of bilingual speech communities. He suggested that Barker's (1947) description of Tucson was insufficient, since it listed only four speech situations: intimate, informal, formal, and inter-group discourse. Weinreich argued that Barker's taxonomy was "insufficiently articulated" (87) to describe all potential organizations of bilingual speech events. He contended that anthropology should look to linguistics particularly to structuralism - in order to properly describe the practice of bilingual speech, and the language acquisition/socialization process that takes place in bilingual communities. 
Weinreich's description of switching $\operatorname{codes}^{3}$ suggested that bilingual individuals possess two separate linguistic varieties, which (ideally) they employ on separate occasions. He suggested that frequent alternation, such as that Barker described among Tucson youth, was a product of poor parenting. Regular code switchers, Weinreich speculated, "in early childhood, were addressed by the same familiar interlocutors indiscriminately in both languages" (74). ${ }^{4}$ This indiscriminate use differed from the ideal bilingual of Weinreich's imagination.

Vogt's (1954) article, though very much inspired by Weinreich (1953), is much less apprehensive about bilingual code switching.

Code-switching in itself is perhaps not a linguistic phenomenon, but rather a psychological one, and its causes are obviously extralinguistic. But bilingualism is of great interest to the linguist because it is the condition of what has been called interference between languages. [Vogt 1954:368]

Vogt assumes that code switching is not only natural, but common. He suggests that all languages - if not all language users - experience language contact, and that contact phenomena, including language alternation, are an important element of language change.

The phenomenon of diglossia, first described by Ferguson (1959), and later refined by Fishman (1967), is another precursor to linguistic analyses of code switching. Ferguson defined diglossia as the existence of a "divergent, highly codified" (1959:336) variety of language, which is used only in particular situations. Although Ferguson limited diglossia to varieties of the same language, Fishman (1967) described similar functional divisions between unrelated languages. Neither Ferguson nor Fishman cite examples of alternation between varieties within a single interaction or discourse. However, their descriptions of diglossia bear on the notion of situational switching. Furthermore, Fishman, citing an unpublished paper by Blom and Gumperz, mentions that varieties may be employed for humor or emphasis in a process of metaphorical switching (Fishman 1967:36). Thus, Fishman's account of diglossia at least seems to have been

${ }^{3}$ The notion of "switching codes" appears to have been borrowed from information theory. Weinreich refers to Fano 1950, a paper also referenced by Jakobson (1971a [1953], 1971b [1961]; Jakobson and Halle 1956) in his discussions of code switching. Fuller exploration of these links is unfortunately beyond the scope of the present paper. See Alvarez-Cáccamo $(1998,2000)$ for more detail.

${ }^{4}$ For discussion of the one-person-one-language ideology in language acquisition see Romaine (1989). 
inspired by the nascent theory of situational and metaphorical switching (Blom and Gumperz 1972; see below). ${ }^{5}$

Erving Goffman $(1979,1981)$ described footing as a process in interaction similar to some functional descriptions of code switching. Indeed, Goffman cites several of Gumperz's descriptions of code switching as examples of footing. The difference he draws between his own theory of footing and Gumperz's and others' descriptions of code switching is a formal one. Whereas code switching (at least for Goffman) necessarily includes a shift from one language to another, ${ }^{6}$ footing shifts may also be indicated in a variety of ways. Even so, Goffman writes, "For speakers, code switching is usually involved" in footing shifts, "and if not this then at least the sound markers that linguists study: pitch, volume, rhythm, stress, [or] tonal quality" (Goffman 1981:128).

For Goffman, footing is the stance or positioning that an individual takes within an interaction. Within a single interaction - even within a short span of talk - an individual can highlight any number of different roles. Goffman suggests that changes in purpose, context, and participant role are common in interaction, and offers footing as a useful theory of the multiple positions taken by parties to talk in interaction. During the course of an interaction, an individual is likely to display a number of different stances; much of Goffman's discussion of footing is thus dedicated to switches in footing. Alternating languages, among other linguistic markers, can serve to mark these shifts in context or role.

\subsection{Gumperz: Code switching and contextualization}

Perhaps no sociocultural linguist has been more influential in the study of code switching than John J. Gumperz. His work on code switching and contextualization has been influential in the fields of sociolinguistics, linguistic anthropology, and the sociology of language. Much of Gumperz's early work was carried out in northern India (Gumperz 1958, 1961, 1964a, 1964b), focused on Hindi and its range of dialects. Gumperz 1958 describes three levels - village dialects, regional dialects, and standard Hindi - each of which may be comprised of numerous varieties, and which serve different functions. Gumperz writes, "Most male residents, especially those who travel considerably, speak both the village and the regional dialect. The former is used at home and with other local

\footnotetext{
${ }^{5}$ Fishman also credits Gumperz for expanding the notion of diglossia to include multilingual societies. However, studies Fishman cites as diglossia were labeled by Gumperz as code switching.

${ }^{6}$ It is far from clear that early code switching research assumed such strict separation of languages. Blom and Gumperz 1972, for example, focus on two dialects of spoken Norwegian. Similarly, Fishman states explicitly, "A theory [of diglossia] which tends to minimize the distinction between languages and varieties is desirable for several reasons" (1967:33).
} 
residents; the latter is employed with people from the outside" (1958:669). Thus the relationship between speakers affects the choice of language variety.

The idea that linguistic form is affected by setting and participants as well as topic was influenced in part by Ervin-Tripp (1964). Her definitions of setting, topic, and function provide an important base for the work of Gumperz and others. Her study of bilingual Japanese-born women living in the United States observed considerable correlation between language choice and discourse content, providing an example of "semantic" analysis of language choice that, while influential (e.g. Myers-Scotton 1993), would be criticized as only partial and approximate (e.g. Auer 1984, 1995).

In 1963, while working with the Institute of Sociology at Oslo University, Gumperz met Jan-Petter Blom (Dil 1971). Together, Blom and Gumperz undertook a study of verbal behavior in Hemnesberget, a small settlement of about 1,300 people in Northern Norway. Gumperz (1964b) compared the use of two dialects, standard literary Bokmål and local Ranamål, in Hemnesberget to the use of standard and local dialects of Hindi in northern India. In each population, the local dialect appeared more frequently in interaction with neighbors, while the standard dialect was reserved for communication across "ritual barriers" (148) barriers of caste, class, and village groupings in India, and of academic, administrative, or religious setting in Norway. On the basis of these comparisons, Gumperz argued that verbal repertoire is definable in social as well as linguistic terms. Distinct repertoires are identified in terms of participants, setting, and topic, and then described in terms of phonological and morphological characteristics.

Blom and Gumperz (1972) expanded the analysis of the functions of Bokmål and Ranamål in Hemnesberget in what has come to be a touchstone in code switching research. They described Bokmål and Ranamål as distinct codes, though not distinct languages. The codes are distinguished by extensive though slight phonological, morphological and lexical differences, as well as native speakers' belief that the two varieties are separate, and tendency to maintain that separation of form. Blom and Gumperz asked why, despite their substantial similarities, and the fact that most speakers commanded both varieties, Bokmål and Ranamål were largely maintained as separate. "The most reasonable assumption," they argued, "is that the linguistic separateness between dialect and standard... is conditioned by social factors" (417). Thus, each variety was seen as having low level differences in form, as well as somewhat distinct social functions.

Blom and Gumperz posited that social events, defined in terms of participants, setting, and topic, "restrict the selection of linguistic variables" (421) in a manner that is somewhat analogous to syntactic or semantic restrictions. That is, in particular social situations, some linguistic forms may be more appropriate than others. Among groups of men greeting each other in workshops along the fjord, the variety of language used differed from that used by teachers presenting text material in the public school, for example. It is important to recognize that 
different social events may, for example, involve the same participants in the same setting when the topic shifts. Thus, teachers reported that they treated lecture versus discussion within a class as different events. While lectures were (according to teachers' reports) delivered in the standard Bokmål, a shift to the regional Ranamål was used to encourage open debate. Blom and Gumperz call this type of shift, wherein a change in linguistic form represents a changed social setting, situational switching (424).

The definition of metaphorical switching relies on the use of two language varieties within a single social setting. Blom and Gumperz describe interactions between clerks and residents in the community administration office wherein greetings take place in the local dialect, but business is transacted in the standard.

In neither of these cases is there any significant change in definition of participants' mutual rights and obligations. ... The choice of either (R) or (B)... generates meanings which are quite similar to those conveyed by the alternation between ty and $v y$ in the examples from Russian literature cited by Friedrich [1972]. We will use the term metaphorical switching for this phenomenon. [Blom and Gumperz 1972:425]

Blom and Gumperz suggest that the use of local (R) phrases in a standard (B) conversation allude to other social events in which the participants may have been involved. This allusion lends some connotative meaning, such as confidentiality, to the current event, without changing the topic or goal.

The notions of situational and metaphorical switching were taken up by a great many sociolinguists, linguistic anthropologists, etc. Whereas Blom and Gumperz identified Ranamål and Bokmål as "codes in a repertoire" (414) and went to some pains to describe the formal differences between the two, many subsequent scholars have been content to equate code with language, and focus their analyses on either functional distributions, or the definition of situations.

Critics have pointed out that Blom and Gumperz (1972) provide scant detail of actual language use in their description of the verbal repertoire of Hemnesberget. Maehlum (1996) is particularly critical of the suggestion that Bokmål and Ranamål comprise separate codes. She argues that, in other rural areas of Norway, local and standard dialects are not nearly as discrete as Blom and Gumperz suggest. Thus, any suggestion that the verbal repertoire of Norwegian speakers is comprised by two distinct codes is flawed. Maehlum suggests that "local" and "standard" exist not as empirically identifiable, discrete codes, but "as idealized entities: it is their existence as norms which is important" (1996:753, original italics). Further, certain phonological or lexical/morphological variables are particularly salient as indicators of particular dialects. This suggests that sociolinguistic variants are available as indexes of various social meanings, but that attempts to define particular codes and the situations in which they occur are problematic. It is perhaps preferable, then, to identify the formal signals of situation or identity available to a group of speakers, and the uses made of these 
signals, rather than to assume a priori that dialects, varieties, or languages will be equally salient across groups.

More than many subsequent scholars, Gumperz seems to have recognized the imperfection of the description of switching as either situational or metaphorical. By 1982, Gumperz's preferred terminology was conversational code switching. (The description and definition of conversational code switching was, however, largely in terms of metaphorical switching.) Gumperz acknowledged that it is generally difficult for analysts to identify particular language choices as situational or metaphorical, and that native speakers generally have few intuitions about or recognition of their own conversational code switches. Except in cases of diglossia, the association between linguistic form and settings, activities, or participants is highly variable, and rarely definable by static models.

Since conversational code switching is not amenable to intuitive methods, and not strictly relatable to macro-sociological categories, Gumperz (1982) argued that close analysis of brief spoken exchanges is necessary to identify and describe the function of code switching. On the basis of his analyses of several speech communities, Gumperz suggested a list of six code switching functions which "holds across language situations" (75), but is "by no means exhaustive" (81). Gumperz suggested quotation marking, addressee specification, interjection, reiteration, message qualification, and "personalization versus objectivization"s (80) as common functions of conversational code switching. It is noteworthy that the functions of code switching that Gumperz identifies are quite similar to the contextualization cues he describes elsewhere in the volume. ${ }^{9}$

Code switching signals contextual information equivalent to what in monolingual settings is conveyed through prosody or other syntactic or lexical processes. It generates the presuppositions in terms of which the content of what is said is decoded. [Gumperz 1982:98]

Like other contextualization cues, language alternation may provide a means for speakers to signal how utterances are to be interpreted-i.e. provide information beyond referential content.

\footnotetext{
${ }^{7}$ Gumperz (1982) points out that both subjects in Hemnesberget and Spanish-English bilinguals in the United States denied any alternation of linguistic form, but even after listening to recordings of themselves and "promising" to refrain from switching, persisted in code switching.

8 The category of "personalization versus objectivization" is somewhat fuzzy, but relates to illocutionary force, evidentiality, and speaker positioning.

${ }^{9}$ Gumperz, it may be said, makes the comparison in reverse. His discussion of contextualization conventions (Gumperz 1982, chapter 6) says that they are "meaningful in the same sense that... the metaphorical code switching of chapter 4 [is] meaningful" (139).
} 
Gumperz's list of code switching functions inspired many subsequent scholars to refine or propose their own lists of functions (e.g. McClure and McClure 1988; Romaine 1989; Nishimura 1997; Zentella 1997). However, as Auer (1995) suggests, the functions suggested by such lists are often ill defined. The oft-cited category of reiteration, for example, fails to define exactly what is repeated, or why. Lists also tend to combine linguistic structures (such as interjection) and pragmatic or conversational functions (message qualification, addressee specification) without attempting to trace the relationship between forms and functions. Although such lists may provide a useful step in the understanding of conversational code switching, they are far from a satisfactory answer to the questions of why switching occurs as it does and what functions it serves in conversation. Noting a number of studies that have, following Gumperz (1982) suggested similar taxonomies of functions, Bailey (2002) notes, "The ease with which such categories can be created - and discrepancies between the code switching taxonomies at which researchers have arrived - hint at the epistemological problems of such taxonomies" (77). Code switching may serve any of a number of functions in a particular interaction, and a single turn at talk will likely have multiple effects. Therefore, any finite list of functions will be more or less arbitrary. Again, the suggestion is that it will be preferable to observe actual interaction, rather than starting from assumptions about the general effects of code switching.

\section{Sociocultural studies of code switching}

Code switching scholarship within sociocultural linguistics may be divided into several (sometimes overlapping) streams. For the purposes of this paper, three broad areas will be discussed: the social psychological approach of Myers-Scotton's markedness model (1983, 1993, 1998) and related work; analyses of identity and code choice; and studies of the effect of code switching on talk in interaction. This last category, largely based on conversation analysis, tends to view code switching behavior both as a method of organizing conversational exchange and as a way to make knowledge of the wider context in which conversation takes place relevant to an ongoing interaction. Since this wider knowledge is usually analyzable at least partially in terms of identity, the separation between what I here call "interaction and code switching" versus "identity and code switching" is neither absolute nor unambiguous. Indeed, the three-part division suggested here should be seen as one of analytic convenience, rather than significant theoretical import. 


\subsection{Myers-Scotton's Markedness}

Carol Myers-Scotton described her markedness model in the book Social Motivations for Codeswitching: Evidence from Africa (1993). ${ }^{10}$ According to Myers-Scotton, each language in a multilingual community is associated with particular social roles, which she calls rights-and-obligations (RO) sets (84). By speaking a particular language, a participant signals her understanding of the current situation, and particularly her relevant role within the context. By using more than one language, speakers may initiate negotiation over relevant social roles. Myers-Scotton assumes that speakers must share, at least to some extent, an understanding of the social meanings of each available code. If no such norms existed, interlocutors would have no basis for understanding the significance of particular code choices.

The markedness model is stated in the form of a principle and three maxims. The negotiation principle, modeled on Grice's (1975) cooperative principle, presents the theory's central claim.

Choose the form of your conversational contribution such that it indexes the set of rights and obligations which you wish to be in force between the speaker and addressee for the current exchange. [Myers-Scotton 1993:113, original italics]

Three maxims follow from this principle. The unmarked choice maxim directs, "Make your code choice the unmarked index of the unmarked RO set in talk exchanges when you wish to establish or affirm that RO set" (114). The marked choice maxim directs, "Make a marked code choice... when you wish to establish a new RO set as unmarked for the current exchange" (131). The exploratory choice maxim states, "When an unmarked choice is not clear, use CS [code switching] to make alternate exploratory choices as candidates for an unmarked choice and thereby as an index of an RO set which you favor" (142). Thus, the social meanings of language (code) choice, as well as the causes of alternation, are defined entirely in terms of participant rights and obligations.

Some critics of the markedness model argue that it relies too heavily on external knowledge, including assumptions about what speakers understand and believe. Auer (1998) argues that it is possible to account for code switching behavior without appeal to the "conversation-external knowledge about language use" (10) required by the markedness model. Of course, it is possible for the

\footnotetext{
${ }^{10}$ Myers-Scotton discussed similar issues and developed the markedness model in code choice prior to the publication of this book (e.g. Myers-Scotton 1972, 1976, 1983). Myers-Scotton 1983 actually laid out the Negotiation Principle and six maxims, including the unmarked choice and exploratory choice maxims that figure in the refined model. However, as the fullest expression of the model, it is Myers-Scotton 1993 that has influenced much subsequent work.
} 
analyst to learn which languages are typically used in particular situations via, for example, ethnographic observation. Furthermore, one can argue that speakers learn these norms as part of the language socialization process. A stronger criticism remains, however: The markedness model requires the analyst to make assumptions about each individual speaker's knowledge and understanding of the speech situation. Code switching is then explained on the basis of the analyst's assumptions about speakers' internal states (including shared judgments about rights and obligations) rather than its effects on the conversation at hand. Further, Auer (1995) points out that empirical studies have failed to reveal the strong correlations between particular languages and speech activities that the markedness model predicts.

Nevertheless, the markedness model is probably the most influential and most fully developed model of code switching motivations. Myers-Scotton continues to refine the model in ways that are consistent with current research on contact linguistics (Myers-Scotton 1998; Myers-Scotton and Bolonyai 2001) and the so-called standard theory (Chomsky 1965) of linguistics (Myers-Scotton and Jake 2001; Jake, Myers-Scotton and Gross 2002).

\subsection{Identity and code switching}

Whereas the markedness model and subsequent work seeks to provide a systematic and generalizable account of the process of code switching, much work in linguistic anthropology, sociolinguistics, and other areas of sociocultural linguistics provide interpretive and interactional understandings of code switching in particular contexts. Although this school of sociocultural linguistics has produced its share of broad theoretical work (e.g. Milroy and Muysken 1995; Alvarez-Cáccamo 1998, 2000; Woolard 2004), it is generally more closely tied to the observation of behavior in particular settings than to generally applicable explanations of linguistic capability. Such studies stand as illustrations of the place of code switching in particular social and historical settings, rather than as models for a universal practice or potential (Heller 1992).

Monica Heller's ethnographic observations and sociolinguistic study in Quebec and Ontario have led her to consider the economics of bilingualism ${ }^{11}$, and to view code switching as a political strategy (Heller 1988b, 1992, 1995, 1999). Since languages tend to become associated with idealized situations and groups of speakers, the use of multiple languages "permits people to say and do, indeed to be two or more things where normally a choice is expected" (Heller 1988b:93). This strategic ambiguity allows anglophones in Quebec, for example, to achieve a position in francophone controlled corporate culture, while still laying claim to an

\footnotetext{
${ }^{11}$ Nor is Heller unique in brining such an economic perspective to discourse strategies. Compare Gal (1979, 1988), Woolard (1985), Hill (1985), et alia.
} 
anglophone identity, with its associated value on the international market. By uniting Bourdieu's (1977) concept of symbolic capital with Gumperz's (1982) discussion of verbal repertoires, Heller $(1992,1995)$ argues that dominant groups rely on norms of language choice to maintain symbolic domination, while subordinate groups may use code switching to resist or redefine the value of symbolic resources in the linguistic marketplace.

While Heller and others describe the relationship between language and identity in economic or class terms, many scholars have focused on social categories such as ethnicity. Rampton's (1995) work on crossing, a type of code switching practiced by speakers across boundaries of ethnicity, race, or language 'community,' ${ }^{12}$ examines the language behavior of Asian, Afro-Caribbean, and Anglo adolescents in 'Ashmead,' UK. Language varieties - Creole, Panjabi, and stylized Asian English - typically associated with an ethnic group, are used by non-members to accomplish complex functions. While Rampton does find some of the language-crossing-as-mockery discussed in earlier accounts, crossing in various directions also serves to forge a common adolescent group, to dissociate from parents or elders, and to resist endemic stereotypes.

Rampton defines crossing in terms of metaphorical switching (Blom \& Gumperz 1972), but in so doing he complicates the notions of situational and metaphorical switching, and of contextualization, considerably. He defines situational switching as language alternation (Auer 1984) which accomplishes contextualization (Gumperz 1982). Rampton reminds us that the boundaries of metaphor are not clear cut (cf. Lakoff \& Johnson 1980); similarly, metaphorical and situational switching cannot be easily delimited. His primary interest, though, is in "figurative" code alternation, a category which, for Rampton, is identical to double voicing (Bakhtin 1981). Unlike situational switching, which Rampton argues simply replaces the current situational frame with a new one, crossing adds additional contexts through which an interaction must be interpreted.

Issues of race, ethnicity, and crossing, as well as economic issues of class and domination are prominent in Bailey's (2001, 2002) work on language and identity among Dominican Americans. Bailey's work focuses on Dominican American youth - young people born in the United States to parents from the Dominican Republic - living in Providence, Rhode Island. Dominican Americans, according to Bailey $(2001,2002)$ define their ethnic affiliation as at once nonWhite and non-Black. That is to say, while, like their African-American peers, Bailey's subjects view themselves as outside the dominant racial category "White," they also reject identification with African Americans based on

${ }^{12}$ Code switching or crossing as a means to negotiate or comment on ethnic or racial identities is also seen in the work of Nishimura (1992), Bucholtz (1999), Lo (1999), Jaffee (2000), Torras and Gafaranga (2002), et alia. 
phenotype or ancestry. In discourse, this complex identity is indexed by shifting uses of nonstandard Dominican Spanish, Caribbean Spanish, African American Vernacular English, and other nonstandard English varieties.

Studies of identity and code switching show that close observation of discourse can yield both empirically and theoretically rich understandings of the functions of language variation in social interaction. By tying observations to particular speakers and social actors, rather than moving too readily to discussions of cultural or linguistic norms, scholars can come to detailed, reliable understandings of the place of language in the construction and transmission of social traditions.

\subsection{Interaction and code switching}

Close observation of discourse is also a hallmark of interactional linguistics, which seeks to understand "the way in which language figures in everyday interaction and cognition" (Ochs, Schegloff and Thompson 1996:2). These studies tend to be greatly inspired by conversation analysis, as well as functional linguistics and linguistic anthropology. A number of studies under this broad umbrella describe both the place of code switching in the language of turn and sequence and the ways that language alternations, like other contextualization cues, make broader contextual knowledge relevant to an ongoing discourse.

Auer's 1984 Bilingual Conversation presented a pioneering study of interaction and code switching. Auer argued that Gumperz's conception of situation is problematic, in that it is defined externally, and from the perspective of the analyst. While Auer acknowledged that Gumperz's own uses of situational and metaphorical are less clear-cut that some scholars have taken them to be, he nonetheless disapproved of the distinction.

[Based on Blom \& Gumperz 1972] one would either have to conclude that (in the situational case) code-switching is without social meaning because it is a necessary consequence of certain situational parameters, or that (in the metaphorical case) it is dependent on an (almost) one-to-one-relationship between language choice and situational parameters which can be purposefully violated. [Auer 1984:4]

Far from pre-existing and determining language choice, Auer argues that situation is created by talk in interaction. The form of each speaker's utterances helps to define the unfolding situation. Further, this negotiation itself has social meaning.

Auer's analyses of Italian migrant children in Germany did not find significant correlation between topic and language use. He suggests that code switching is not essentially 'semantic' in nature, not derived from the 'meanings' of the available languages, but rather is "embedded in the sequential development of the conversation" (1984:93). Auer found a great preference for subsequent speakers to maintain the language of the previous turn. Language alternation was

then available to mark contrast, either to bracket a sequence from the preceding 
discourse or to negotiate a common language. Auer recommended this procedural analysis of language alternation over individualistic analyses based on introspection, or macro-sociological approaches that define the meaning of potential language choices outside of actual language use.

Several subsequent studies have examined sequential or interactional functions of language alternation. Conversation analysts have suggested that code switching may serve to enhance turn selection (Li Wei 1998; Cromdal 2001) or soften refusals (Bani-Shoraka 2005; Li Wei 2005), and is a possible resource to accomplish repair (Auer 1995; Sebba and Wooten 1998) or mark dispreferred ${ }^{13}$ responses (Li Wei 1998; Bani-Shoraka 2005). In addition to these interactional functions, empirical studies have examined how switches in language variety make particular elements of situation, speaker identities, or background relevant to ongoing talk (e.g. Li Wei 1998, 2002; Gafaranga 2001).

Stroud (1998) criticizes approaches to code switching based too strictly in conversation analysis. He suggests that $\mathrm{CA}$, by proscribing argument from ethnographic or macro-sociological evidence, cannot provide satisfactory analysis of language behavior in non-Western settings. Stroud observes, "[L]anguage use and patterns of code-switching both structure and are structured by indigenous cultural practices" (1998:322), a suggestion that many sociocultural linguists would probably tend to accept. If analysts then ignore cultural information not visible (to them) within discourse data, their analyses risk missing important elements of function and meaning. Stroud maintains, "My argument is that conversational code-switching is so heavily implicated in social life that it cannot really be understood apart from an understanding of social phenomena" (1998:322). This vital understanding is often provided by analysts' focus on populations that they are themselves a part of; however, it may also be desirable to undertake some broader examination of the social context within which discourse takes place.

It seems clear that, in order for observations about the contextualizing functions of language use to have validity and reliability, they should be based on close observation of discourse. At the same time, it should not be assumed that all elements relevant to discourse and social interaction are visible to the analyst, particularly when the analyst is not embedded in the particular social structures he or she is studying. We should remember Stroud's (1998) suggestion that discourse analysis be grounded in an understanding of the society within which communication takes place. The optimal approach to understanding these phenomena would thus seem to include ethnographic observation with close

\footnotetext{
${ }^{13}$ In conversation analysis terms, responses which serve to accomplish the projected action of a previous turn are generally considered preferred, while those that work against such accomplishment are dispreferred. For further explanation, see Sacks, Schegloff and Jefferson 1974 and Hutchby and Woofit 1998.
} 
analysis of discourse, providing an empirical warrant for any theory of discourse interaction.

\section{Integrated definitions}

A great many scholars in sociocultural linguistics use a definition of code switching similar to Heller's: "the use of more than one language in the course of a single communicative episode" (1988a:1). Auer and Myers-Scotton, who largely disagree on how or why code switching occurs, nonetheless sound quite similar in their definitions of the phenomenon. Auer (1984:1) refers to "the alternating use of more than one language," while Myers-Scotton (1993:vii) mentions "the use of two or more languages in the same conversation." Romaine (1989) cites Gumperz as the source of this definition. However, these definitions introduce an element not strictly present in Gumperz's definition: "Conversational code switching can be defined as the juxtaposition within the same speech exchange of passages of speech belonging to two different grammatical systems or subsystems" (Gumperz 1982:59).

Note that Gumperz's original definition refers to "grammatical systems or subsystems," while the subsequent restatements refer to languages. While the former is scarcely more concrete or less ambiguous than the latter, it need not be assumed that the two terms are identical. The plural languages seems to suggest discrete varieties (as English, Spanish, Kiswahili, etc.), while the more equivocal "systems or subsystems" might equally imply languages or elements of a language, such as lexical items, syntactic constructions, and prosodic phenomena. This list of grammatical subsystems is very similar to Goffman's (1979) list of footing cues and virtually identical to Gumperz's (1982) preliminary list of contextualization cues.

The attempt to define language and languages is a perennial controversy in linguistics. By defining code simply as a language (or variety of language) without first defining these basic terms, scholars have essentially put off what should be a foundational question. Alvarez-Cáccamo (1990, 1998, 2000) provides exceptional attempts to define code and code switching. His discussion relies in turn on work by Jakobson (1971b; Jakobson, Fant and Halle 1952, inter alia) and Gumperz (1982, 1992, inter alia). Alvarez-Cáccamo (1998) points out that for Jakobson, an early adopter of the term code switching who was influenced by information theory, languages have codes; they do not comprise codes. A language user thus makes use of a code or codes when speaking, listening, etc. The precise nature of any language user's codes cannot be ascertained by an analyst nor by fellow speakers.

Internal individual codes (senders' and receivers') must necessarily differ, as they belong to different minds. But all human minds are also uniquely alike: they produce language and communication, which are formidably universal. Therefore, the question whether each person possesses "different"... codes is parallel to the question 
whether speakers of the "same" language share a grammar, or whether culture, ideology, etc., is also shared. There are no absolute answers to this, only a pragmatic one: does communication between two persons sufficiently work? [AlvarezCáccamo, personal communication]

Speakers use communicative codes in their attempts (linguistic or paralinguistic) to communicate with other language users. Listeners use their own codes to make sense of the communicative contributions of those they interact with. Listeners may need to shift their expectations to come to a useful understanding of speakers' intentions. Similarly, speakers may switch the form of their contributions in order to signal a change in situation, shifting relevance of social roles, or alternate ways of understanding a conversational contribution. In other words, switching codes is a means by which language users may contextualize communication.

A useful definition of code switching for sociocultural linguistic analysis should recognize it as an alternation in the form of communication that signals a context in which the linguistic contribution can be understood. The 'context' so signaled may be very local (such as the end of a turn at talk), very general (such as positioning vis-à-vis some macro-sociological category), or anywhere in between. Furthermore, it is important to recognize that this signaling is accomplished by the action of participants in a particular interaction. That is to say, it is not necessary or desirable to spell out the meaning of particular code switching behavior a priori. Rather, code switching is accomplished by parties in interaction, and the meaning of their behavior emerges from the interaction. This is not to say that the use of particular linguistic forms has no meaning, and that speakers "make it up as they go." Individuals remember and can call on past experiences of discourse. These memories form part of a language user's understanding of discourse functions. Therefore, within a particular setting certain forms may come to recur frequently. Nonetheless, it is less interesting (for the current author at least, and probably for the ends of sociocultural linguistic analysis) to track the frequency or regularity of particular recurrences than to understand the effect of linguistic form on discourse practice and emergent social meanings.

To recapitulate, then, code switching is a practice of parties in discourse to signal changes in context by using alternate grammatical systems or subsystems, or codes. The mental representation of these codes cannot be directly observed, either by analysts or by parties in interaction. Rather, the analyst must observe discourse itself, and recover the salience of a linguistic form as code from its effect on discourse interaction. The approach described here understands code switching as the practice of individuals in particular discourse settings. Therefore, it cannot specify broad functions of language alternation, nor define the exact nature of any code prior to interaction. Codes emerge from interaction, and become relevant when parties to discourse treat them as such. 


\section{References}

Alvarez-Cáccamo, Celso. 1990. "Rethinking Conversational Code-Switching: Codes, Speech Varieties, and Contextualization.” In Kira Hall, Jean-Pierre Koenig, Michael Meacham, Sondra Reinman and Laurel Sutton (eds.) Proceedings of the Sixteenth Annual Meeting of the Berkeley Linguistics Society, 3-16. Berkeley: Berkeley Linguistics Society.

--. 1998. "From 'Switching Code' to 'Code-switching': Towards a Reconceptualization of Communicative Codes." In Peter Auer (ed.) CodeSwitching in Conversation: Language, Interaction, and Identity, 29-48. London: Routledge.

--. 2000. "Para um Modelo do 'Code-switching' e a Alternancia de Variedades como Fenomenos Distintos: Dados do Discurso Galego-Portuges/Espanhol na Galiza" (Toward a Model of 'Code-switching' and the Alternation of Varieties as Distinct Phenomena: Data from Galician Portuguese/Spanish Discourse in Galicia). Estudios de Sociolinguistica 1(1): 111-128.

Auer, Peter. 1984. Bilingual Conversation. Amsterdam: John Benjamins.

--. 1995. "The Pragmatics of Code-switching: A Sequential Approach." In Lesley Milroy and Pieter Muysken (eds.) One Speaker, Two Languages: Crossdisciplinary Perspectives on Code-switching, 115-135. Cambridge: Cambridge University Press.

--. 1998. Code-switching in Conversation: Language, Interaction, and Identity. London: Routledge.

Azuma, Shoji. 1991. "Two Level Processing Hypothesis in Speech Production: Evidence from Intrasentential Code-switching." Papers from the Regional Meetings, Chicago Linguistic Society, 27(1): 16-30.

Bailey, Benjamin. 2001. "The Language of Multiple Identities among Dominican Americans." Journal of Linguistic Anthropology 10(2): 190-22

--. 2002. Language, Race, and Negotiation of Identity: A Study of Dominican Americans. New York: LFB Scholarly Publishing.

Bakhtin, Mikhail. 1981. The Dialogic Imagination. Caryl Emerson and Michael Holquist (trans.). Austin: University of Texas Press.

Bani-Shoraka, Helena. 2005. Language Choice and Code-switching in the Azerbaijani Community in Tehran: A Conversation Analytic Approach to Bilingual Practices. Uppsala, Sweden: Acta Universitatis Upsaliensis.

Barker, George. 1947. "Social Functions of Language in a Mexican-American Community." Acta Americana 5: 185-202.

Belazi, Heidi, Edward Rubin, and Almeida Jacqueline Toribio. 1994. "Code Switching and X-Bar Theory: The Functional Head Constraint." Linguistic Inquiry 25(2): 221-237.

Benson, Erica. 2001. "The Neglected Early History of Codeswitching Research in the United States." Language \& Communication 21: 23-36.

Blom, Jan-Petter, and John Gumperz. 1972. "Social Meaning in Linguistic Structures: Code Switching in Northern Norway." In: John Gumperz and Del 
Hymes (eds.): Directions in Sociolinguistics: The Ethnography of Communication, 407-434. New York: Holt, Rinehart, and Winston.

Bordieu, Pierre. 1977. "The Economics of Linguistic Exhanges.” Social Science Information 16, 645-668.

Bucholtz, Mary. 1999. "You da Man: Narrating the Racial Other in the Production of White Masculinity." Journal of Sociolinguistics 3(4): 443-460.

Bucholtz, Mary, and Kira Hall. 2005. "Identity and Interaction: A Sociocultural Linguistic Approach.” Discourse Studies 7(4-5).

Cenoz, Jasone and Fred Genesee. 2001. Trends in Bilingual Acquisition. Amsterdam: John Benjamins.

Chomsky, Noam. 1965. Aspects of the Theory of Syntax. Cambridge, MA: MIT Press.

Cromdal, Jakob. 2001. "Overlap in Bilingual Play: Some Implications of CodeSwitching for Overlap Resolution." Research on Language and Social Interaction 34(4): 421-451.

Dil, Anwar S. 1971. "Introduction." In John J. Gumperz, Language in Social Groups: Essays by John J. Gumperz. Stanford: Stanford University Press.

DiSciullo, Anna-Maria, and Edwin Williams. 1987. On the Definition of a Word. Cambridge, MA: MIT Press.

Ervin-Tripp, Susan. 1964. "An Analysis of the Interaction of Language, Topic and Listener." American Anthropologist 66(6): part 2, 86-102.

Fano, Robert M. 1950. "The Information Theory Point of View in Speech Communication." Journal of the Acoustical Society of America 22, 691-696.

Ferguson, Charles. 1959. "Diglossia." Word 15, 325-340.

Fishman, Joshua. 1967. "Bilingualism with and without Diglossia; Diglossia with and without Bilingualism." Journal of Social Issues 23(2): 29-38.

Fotos, Sandra. 2001. "Codeswitching By Japan's Unrecognized Bilinguals: Japanese University Students' Use Of Their Native Language As A Learning Strategy." In Mary Goebel Noguchi and Sandra Fotos (eds.) Studies in Japanese Bilingualism. Clevedon: Multilingual Matters.

Friedrich, Paul. 1972. "Social Context and Semantic Feature: The Russian Pronominal Usage." In John Gumperz and Dell Hymes (eds.) Directions in Sociolinguistics: The Ethnography of Communication, 270-300. New York: Holt, Rinehart and Winston.

Gafaranga, Joseph. 2001. "Linguistic Identities in Talk-in-Interaction: Order in Bilingual Conversation.” Journal of Pragmatics 33(12): 1901-1925.

Gal, Susan. 1979. Language Shift: Social Determinants of Linguistic Change in Bilingual Austria. New York: Academic Press.

--. 1988. "The Political Economy of Code Choice." In Monica Heller (ed.) Codeswitching: Anthropological and Sociolinguistic Perspectives, 243-261. Berlin: Mouton de Gruyter.

Grice, H. Paul. 1975. "Logic and Conversation." In Peter Cole and Jerry L. Morgan (eds.): Speech Acts, 41-55. New York: Academic Press.

Goffman, Erving. 1979. "Footing." Semiotica 25, 1-29. 
--. 1981. Forms of Talk. Philadelphia: University of Pennsylvania Press.

Gumperz, John. 1958. "Dialect Differences and Social Stratification in a North Indian Village." American Anthropologist 60, 668-681.

--. 1961. "Speech Variation and the Study of Indian Civilization." American Anthropologist 63, 976-988.

--. 1964a. "Hindi-Punjabi Code-switching in Delhi." In H. Hunt (ed.): Proceedings of the Ninth International Congress of Linguistics, 1115-1124. The Hague: Mouton.

--. 1964b. "Linguistic and Social Interaction in Two Communities." American Anthropologist 66(6): part 2, 137-153.

--. 1982. Discourse Strategies. Cambridge: Cambridge University Press.

--. 1992. "Contextualization Revisisted." In Peter Auer and Aldo di Luzo (eds.) The Contextualization of Language, 39-53. Amsterdam: John Benjamins.

Halmari, Helena. 1997. Government and Codeswitching: Explaining American Finnish. Amsterdam: John Benjamins.

Heller, Monica. 1988a. Codeswitching: Anthropological and Sociolinguistic Perspectives. Berlin: Mouton de Gruyter.

--. 1988b. "Strategic Ambiguity: Code-switching in the Mangagement of Conflict." In Monica Heller (ed.) Codeswitching: Anthropological and Sociolinguistic Perspectives, 77-96. Berlin: Mouton de Gruyter.

--. 1992. "The Politics of Codeswitching and Language Choice." In Carol Eastman (ed.) Codeswitching, 123-142. Clevedon: Multilingual Matters.

--. 1995. "Code-switching and the Politics of Language." In Lesley Milroy and Pieter Muysken (eds.) One Speaker, Two Languages: Cross-disciplinary Perspectives on Code-switching. Cambridge: Cambridge University Press.

--. 1999. Linguistic Minorities and Modernity: A Sociolinguistic Ethnography. London: Longman.

Hill, Jane. 1985. "The Grammar of Consciousness and the Consciousness of Grammar." American Ethnologist 12(4): 725-737.

Hutchby, Ian and Robin Woofit. 1998. Conversation Analysis: Principles, Practices, and Applications. Malden, MA: Polity Press.

Hymes, Dell. 1964. "Introduction: Toward Ethnographies of Communication." American Anthropologist 66(6): part 2, 1-34.

Jaffe, Alexandra. 2000. "Comic Performance and the Articulation of Hybrid Identity." Pragmatics 10(1): 39-59.

Jake, Janice, Carol Myers-Scotton and Steven Gross. 2002. "Making a Minimalist Approach to Codeswitching Work: Adding the Matrix Language." Bilingualism: Language and Cognition 5(1): 69-91.

Jakobson, Roman. 1971a. "Results of a Joint Conference of Anthropologists and Linguists." In Selected Writings, volume II, 554-567. The Hague: Mouton.

--. 1971b. "Linguistics and Communication Theory." In Selected Writings, volume II, 570-579. The Hague: Mouton. 
Jakobson, Roman, Gunnar Fant and Morris Halle. 1952. Preliminaries to Speech Analysis: The Distinctive Features and their Corelates. Cambridge, MA: MIT Press.

Jakobson, Roman and Morris Halle. 1956. Fundamentals of Language. The Hague: Mouton.

Joshi, Aravind. 1985. "How much Context-sensitivity is Necessary for Assigning Structural Descriptions: Tree Adjoining Grammars." In D. Dowty, L. Karttunen, and A. Zwicky (eds.) Natural Language Parsing. Cambridge: Cambridge University Press.

Lakoff, George and Mark Johnson. 1980. Metaphors we Live By. Chicago: University of Chicago Press.

Li Wei. 1998. "The 'Why' and 'How' Questions in the Analysis of Conversational Code-Switching." In Peter Auer (ed.): Code-Switching in Conversation: Language, Interaction and Identity, 156-176. London: Routledge.

--. 2005. "How can you Tell?' Toward a Common Sense Explanation of Conversational Code-Switching." Journal of Pragmatics 37(3): 375-389.

Lo, Adrienne. 1999. "Codeswitching, Speech Community Membership, and the Construction of Ethnic Identity." Journal of Sociolinguistics 3-4, 461-479.

MacSwann, Jeff. 2000. "The Architecture of the Bilingual Language Faculty: Evidence from Intrasentential Code Switching." Bilingualism: Language and Cognition 3(1): 37-54.

Maehlum, Brit. 1996. "Codeswitching in Hemnesberget - Myth or Reality?" Journal of Pragmatics 25, 749-761.

McClure, Erica and Malcolm McClure. 1988. "Macro- and Micro-sociolinguistic Dimensions of Code-switching in Vingard (Romania)." In Monica Heller (ed.) Codeswitching: Anthropological and Sociolinguistic Perspectives, 25-51. Berlin: Walter de Gruyter.

Milroy, Lesley and Pieter Muysken. 1995. One Speaker, Two Languages: Crossdisciplinary Perspectives on Code-switching. Cambridge: Cambridge University Press.

Myers-Scotton, Carol. 1972. Choosing a Lingua Franca in an African Capital. Edmonton: Linguistic Research.

--. 1976. "Strategies of Neutrality: Language Choice in Uncertain Situations." Language 52(4): 919-941.

--. 1983. "The Negotiation of Identities in Conversation: A Theory of Markedness and Code Choice." International Journal of the Sociology of Language 44, 115-136.

--. 1993. Social Motivations for Codeswitching: Evidence from Africa. Oxford: Clarendon Press.

--. 1998. Codes and Consequences: Choosing Linguistic Varieties. New York: Oxford University Press.

Myers-Scotton, Carol and Agnes Bolonyai. 2001. "Calculating Speakers: Codeswitching in a Rational Choice Model.” Language in Society 30, 1-28. 
Myers-Scotton, Carol and Janice Jake. 2001. "Four Types of Morpheme: Evidence from Aphasia, Code Switching, and Second-Language Acquisition." Linguistics 38(6): 1053-1100.

Nishimura, Miwa. 1992. "Language Choice and In-Group Identity among Canadian Niseis." Journal of Asian Pacific Communication 3(1): 97-113.

--. 1997. Japanese-English Code-switching: Syntax and Pragmatics. New York: P. Lang.

Ochs, Elinor, Emanuel Schegloff and Sandra Thompson. 1996. Interaction and Grammar. Cambridge: Cambridge University Press.

Poplack, Shana. 1980. "Sometimes I'll Start a Sentence in Spanish y Termino en Espanol: Toward a Typology of Code-switching." Linguistics 18(233-234): 581-618.

Rampton, Ben. 1995. Crossing: Language and Ethnicity among Adolscents. London: Longman.

Romaine, Suzanne. 1989. Bilingualism. Oxford: Basil Blackwell.

Sacks, Harvey, Emanuel Schegloff and Gail Jefferson. 1974. "A Simplest Systematics for the Organization of Turn Taking for Conversation." Language 50, 696-735.

Sankoff, David, and Shana Poplack. 1981. "A Formal Grammar for CodeSwitching." Papers in Linguistics 14(1-4): 3-45.

Sapir, Edward. 1929. "The Status of Linguistics as a Science." Language 5(4): 207-214.

Sebba, Mark and Tony Wooten. 1998. "We, They and Identity: Sequential Versus Identity-Related Explanation in Code-Switching." In Peter Auer (ed.): CodeSwitching in Conversation: Language, Interaction and Identity, 262-286. London: Routledge.

Stroud, Christopher. 1998. "Prespectives on Cultural Variability of Discourse and some Implications for Code-switching." In Peter Auer (ed.): Code-Switching in Conversation: Language, Interaction and Identity, 321-348. London: Routledge.

Torras, Maria-Carme and Joseph Gafaranga. 2002. "Social Identities and Language Alternation in Non-Formal Institutional Bilingual Talk: Trilingual Service Encounters in Barcelona." Language in Society 31(4): 527-548.

Vogt, Hans. 1954. "Language Contacts.” Word 10(2-3): 365-374.

Weinreich, Uriel. 1953. Languages in Contact. The Hague: Mouton.

Woolard, Katherine. 1985. "Language Variation and Cultural Hegemony." American Ethnologist 12(4): 738-748.

--. 2004. "Codeswitching." In Alessandro Duranti (ed.) A Companion to Linguistic Anthropology, 73-94. Malden, MA: Blackwell.

Zentella, Ana Celia. 1997. Growing Up Bilingual. Malden, MA: Blackwell. 